\title{
Prevalence of dual endocrinopathy: hypothyroidism and gestational diabetes mellitus in patients of preeclampsia
}

\author{
Natasha Gupta $^{1}$, Sudhaa Sharma ${ }^{2 *}$, Sunita Jamwal ${ }^{3}$
}

\begin{abstract}
${ }^{1}$ Department of Obstetrics and Gynaecology, All India Institute Medical Sciences (AIIMS), New Delhi, Delhi, India ${ }^{2}$ Department of Obstetrics and Gynaecology, Government Medical College, Jammu, Jammu and Kashmir, India ${ }^{3}$ Department of Obstetrics and Gynaecology, PGIMER, Chandigarh, India
\end{abstract}

Received: 12 July 2019

Accepted: 30 September 2019

\author{
*Correspondence: \\ Dr. Sudhaa Sharma, \\ E-mail: sudhaagynaec@gmail.com
}

Copyright: () the author(s), publisher and licensee Medip Academy. This is an open-access article distributed under the terms of the Creative Commons Attribution Non-Commercial License, which permits unrestricted non-commercial use, distribution, and reproduction in any medium, provided the original work is properly cited.

\begin{abstract}
Background: Hypertension associated with proteinuria greater than $0.3 \mathrm{~g} / \mathrm{L}$ in a 24-hour urine collection or $1+$ by qualitative urine examination, after 20 weeks of gestation is preeclampsia. The present study was conducted to evaluate prevalence of dual endocrinopathy (hypothyroidism and gestational diabetes mellitus) in patients of preeclampsia.

Methods: The observational study was conducted within a period of one year from November 2015 to October 2016 in the Department of Obstetrics and Gynaecology SMGS Hospital, GMC, Jammu. A total of 400 patients of preeclampsia were included in the study and underwent serum TSH and oral glucose tolerance test.

Results: In this study $32.5 \%$ of the preeclampsia patients (130 out of 400) had hypothyroidism, 15.25\% patients (61 out of 400 preeclampsia) had gestational diabetes mellitus, $9.75 \%$ patients of preeclampsia had dual endocrinopathy (both hypothyroidism and gestational diabetes mellitus).

Conclusions: The current study concluded that dual endocrinopathy (both hypothyroidism and gestational diabetes mellitus) has substantially higher prevalence $(9.75 \%)$ in the patients of preeclampsia.
\end{abstract}

Keywords: Dual endocrinopathy, Gestational diabetes mellitus, Hypothyroidism, Preeclampsia

\section{INTRODUCTION}

Preeclampsia is identified in 3.9 percent of all pregnancies. ${ }^{1}$ The World Health Organization systematically reviews maternal mortality worldwide, and in developed countries, 16 percent of maternal deaths were reported to be due to hypertensive disorders. ${ }^{2}$ Importantly more than half of these hypertension related deaths were preventable. ${ }^{3}$

The prevalence of preeclampsia varies in different populations and in different ethnic groups. ${ }^{4}$ African American, Native American, Asian, and Hispanic women are at higher risk for gestational diabetes compared with white women. ${ }^{5}$ Diabetes is the most common medical complication of pregnancy. The incidence of diabetes complicating pregnancy increased approximately 40 percent between 1989 and 2004. ${ }^{6}$

Endothelial dysfunction, an early marker of macrovascular disease, is present in pregnancy complicated by impaired glucose tolerance and gestational diabetes mellitus. This could explain, the increased risk for concurrent hypertensive disorders during pregnancy in diabetic women. ${ }^{7}$ These patients also have increased neonatal morbidity including fetal demise, neonatal hypoglycemia, jaundice, polycythemia and hypocalcemia. ${ }^{8}$ Moreover, maternal diabetes is associated with long term implications on the fetus including increase incidence of future obesity and type II diabetes. 
Hypothyroidism is the second most common endocrinopathy during pregnancy, and its incidence range from $2 \%$ to $5 \%$. Autoimmune thyroiditis (also known as Hashimoto's thyroiditis) and iatrogenic thyroid gland destruction are the most common etiologies for this endocrinopathy in pregnant women. ${ }^{9}$

Thyroid function is very intimately related to the reproductive performance of women. Pregnant women with hypothyroidism experience a higher rate of first trimester abortions, anemia, post-partum hemorrhage, gestational hypertension and placental abruption. ${ }^{10}$

The pathophysiology correlating hypothyroidism and preeclampsia is not clear. Thyroid hormones seem to be important in placentation and regulation of early pregnancy, partly explaining the association between hypothyroidism and preeclampsia. ${ }^{11}$

It was postulated that effect of preeclampsia on thyroid function during pregnancy is mediated by antiangiogenic factor soluble fms like tyrosine kinase (sFlt-1) which is elevated in patients with preeclampsia. ${ }^{12}$

In utero exposure to maternal hypothyroidism increases the risk for miscarriage, intrauterine death and developmental disorders and lower than average IQ later on in life. Fetuses of pregnant women with uncontrolled hypothyroidism are at a greater risk to develop multinodular goiter and have a higher tendency to be small for gestational age. ${ }^{13,14}$

A better understanding of the association between these conditions may lead to more effective strategies for prenatal care and may ultimately lead to better understanding of their pathophysiology. Thus the present study was conducted to evaluate the prevalence of dual endocrinopathy (hypothyroidism and gestational diabetes mellitus) in patients of preeclampsia.

\section{METHODS}

The present cross sectional observational study was conducted within a period of one year from November 2015 to October 2016 in the Department of Obstetrics and Gynaecology SMGS Hospital, GMC Jammu. Total 400 patients diagnosed with preeclampsia (both inpatient and outpatient) were included in the study. Informed consent was obtained from all women.

\section{Inclusion criteria}

\section{- $\quad$ Age 18-45 years}

- Patient with two blood pressure readings of atleast $140 \mathrm{mmHg}$ systolic and/or $90 \mathrm{mmHg}$ diastolic, atleast 6 hours apart after $20^{\text {th }}$ week of gestation with proteinuria $\geq 1+$ by qualitative urine examination or $\geq 0.3 \mathrm{~g} / 1$ in a 24 -hour urine collection after 20 weeks of gestation.

\section{Exclusion criteria}

- Pregnancy with gestational hypertension, eclampsia, chronic hypertension, preeclampsia superimposed on chronic hypertension

- All women with history of renal disease, metabolic disorders and other chronic illnesses during pregnancy

- Multiple pregnancy

- Molar gestation.

\section{Sample collection}

All samples were collected prior to delivery and were sent to hospital laboratory.

Serum TSH levels were measured by chemiluminescence immunoassay (CLIA). The TSH CLIA is based on the principle of a solid phase enzyme linked immunosorbent assay. The following reference ranges of TSH were taken (as recommended by American Thyroid Association 2011).

- First trimester - 0.1 to $2.5 \mathrm{mIU} / \mathrm{L}$

- Second trimester -0.2 to $3.0 \mathrm{mIU} / \mathrm{L}$

- Third trimester -0.3 to $3.0 \mathrm{mIU} / \mathrm{L}$.

In all subjects, Oral Glucose Tolerance Test (OGTT) was done with 75 grams anhydrous glucose and plasma glucose was measured as fasting (after an overnight fast of atleast 8 hours), one and two hours. The diagnosis of gestational diabetes mellitus was made when any of the following plasma glucose values were as follows:

- $\quad$ Fasting blood glucose $\geq 92 \mathrm{mg} / \mathrm{dl}$

- Post $1 \mathrm{hr} \geq 180 \mathrm{mg} / \mathrm{dl}$

- Post $2 \mathrm{hr} \geq 153 \mathrm{mg} / \mathrm{dl}$

For the collection of $24 \mathrm{hr}$ urinary sample, the patients were instructed to void the first morning sample and then start collecting urine in a special container for the next 24 hours and the next morning sample was also collected. Patients were advised to avoid dehydration and strenuous exercise.

The study subjects underwent basic investigations including blood group, CBC, RFTs, LFTs, Blood Sugar and special investigations including Urine for Albumin, 24 hour urinary protein, serum TSH and OGTT.

Prior to urine collection all women were carefully instructed on the procedure of collection. Urine for albumin was sent and 24-hour urine collection was started on the first morning after admission to hospital.

\section{Statistical methods}

The recorded data was compiled and entered in a spreadsheet (Microsoft Excel) and then exported to data 
editor of SPSS Version 20.0 (SPSS Inc., Chicago, Illinois, USA). Continuous variables were expressed as Mean \pm SD and Categorical variables were expressed as percentages. Frequency distribution tables and bar charts were used for data presentation. Chi-square test was employed to determine association of dual endocrinopathy with severity of preeclampsia. p-value less than 0.05 was considered statistically significant.

\section{RESULTS}

Table 1: Age distribution of study patients.

\begin{tabular}{|lll|}
\hline Age (years) & Number of patients & $\%$ \\
\hline $18-24$ & 94 & 23.50 \\
\hline $25-29$ & 180 & 45.00 \\
\hline $30-34$ & 98 & 24.50 \\
\hline$\geq 35$ & 28 & 7.00 \\
\hline Total & $\mathbf{4 0 0}$ & $\mathbf{1 0 0}$ \\
\hline
\end{tabular}

Mean age of patients was Mean $\pm \mathrm{SD}=27.4 \pm 4.21$ years.

Table 2: Distribution of study patients as per gravidity.

\begin{tabular}{|lll|}
\hline Gravidity & Number of patients & $\%$ \\
\hline Primigravida & 247 & 61.75 \\
\hline Multigravida & 153 & 38.25 \\
\hline Total & $\mathbf{4 0 0}$ & $\mathbf{1 0 0}$ \\
\hline
\end{tabular}

According to the study and Table 2 showing distribution of study patients as per gravidity, majority of the patients $61.25 \%$ (247 out of 400 ) in the study were primigravida, followed by $38.25 \%$ (153 out of 400 ) were multigravida.

Table 3: Gestational age (weeks) at diagnosis of preeclampsia among study patients.

\begin{tabular}{|lll|}
\hline Gestational age (weeks) & Number of patients & $\%$ \\
\hline$<32$ & 37 & 9.25 \\
\hline $32-36$ & 122 & 30.50 \\
\hline$>36$ & 241 & 60.25 \\
\hline Total & $\mathbf{4 0 0}$ & $\mathbf{1 0 0}$ \\
\hline
\end{tabular}

Mean \pm SD $($ weeks $)=36.7 \pm 3.95$ weeks

Table 3 shows gestational age (weeks) at diagnosis of preeclampsia among study patients. In our study we divided the patients into 3 groups according to period of gestation, <32 weeks, 32-36 weeks, >36 weeks. According to the above table showing gestational age (weeks), majority of the patients $60.25 \%$ (241 out of 400) were more than 36 weeks period of gestation followed by $30.50 \%$ (122 out of 400 ) of the patients in the 32-36 week group. Only $9.25 \%$ of patients ( 37 out of 400 ) were in the $<32$ week group.

Table 4 shows distribution of study patients as per systolic blood pressure. In present study majority of the patients, 40.25\% (161 out of 400) had systolic BP 140$149 \mathrm{mmHg}$, followed by $35.50 \%$ (142 out of 400) had
Systolic BP 150-160 mmHg. Least number of patients $24.25 \%$ (97 out of 400) had systolic BP 150-160 mmHg.

Mean systolic BP of patients in present study was 153.9 $\mathrm{mmHg}$ with SD of $10.76 \mathrm{mmHg}$.

Table 4: Distribution of study patients as per systolic blood pressure.

\begin{tabular}{|lll|}
\hline Systolic BP (mmHg) & Number of patients & $\%$ \\
\hline $140-149$ & 161 & 40.25 \\
\hline $150-160$ & 142 & 35.50 \\
\hline$>160$ & 97 & 24.25 \\
\hline Total & $\mathbf{4 0 0}$ & $\mathbf{1 0 0}$ \\
\hline
\end{tabular}

Mean \pm SD $(\mathrm{mmHg})=153.9 \pm 10.76$

Table 5: Distribution of study patients as per diastolic blood pressure.

\begin{tabular}{|lll|}
\hline Diastolic BP $(\mathrm{mmHg})$ & Number of patients & $\%$ \\
\hline $90-99$ & 110 & 27.50 \\
\hline $100-110$ & 249 & 62.25 \\
\hline$>110$ & 41 & 10.25 \\
\hline Total & $\mathbf{4 0 0}$ & $\mathbf{1 0 0}$ \\
\hline
\end{tabular}

Mean \pm SD $=103.7 \pm 8.04$

Table 5 shows distribution of study patients as per diastolic blood pressure, majority of the patients, $62.25 \%$ (249 out of 400) had Diastolic BP 100 - $110 \mathrm{mmHg}$, followed by $27.50 \%$ (110 out of 400) had Diastolic BP $90-99 \mathrm{mmHg}$. While only $10.25 \%$ (41 out of 400 ) had Diastolic BP > $110 \mathrm{mmHg}$.

Mean diastolic BP of patients was $103.7 \mathrm{mmHg}$ with SD of $8.04 \mathrm{mmHg}$.

Table 6: Prevalence of hypothyroidism in study patients.

\begin{tabular}{|lll|}
\hline Hypothyroidism & Number of patients & $\%$ \\
\hline Present & 130 & 32.50 \\
\hline Absent & 270 & 67.50 \\
\hline Total & $\mathbf{4 0 0}$ & $\mathbf{1 0 0}$ \\
\hline
\end{tabular}

Table 6 shows the prevalence of hypothyroidism in study patients. In the study, $32.5 \%$ (130 out of 400) had hypothyroidism while $67.50 \%$ (270 out of 400) did not have hypothyroidism. According to the study, mean serum TSH was $2.54 \pm 2.27 \mathrm{mIU} / \mathrm{L}$.

Table 7: Prevalence of GDM in study patients.

\begin{tabular}{|lll|}
\hline $\begin{array}{l}\text { Gestational diabetes mellitus } \\
\text { (interpreted by positive OGTT) }\end{array}$ & $\begin{array}{l}\text { Number } \\
\text { of patients }\end{array}$ \\
\hline Present & 61 & 15.25 \\
\hline Absent & 339 & 84.75 \\
\hline Total & $\mathbf{4 0 0}$ & $\mathbf{1 0 0}$ \\
\hline
\end{tabular}


According to Table 9, showing prevalence of GDM in study patients, $15.25 \%$ (61 out of 400) patients had gestational diabetes mellitus and $84.75 \%$ (339 out of 400) did not have gestational diabetes mellitus.

Table 8: Prevalence of dual endocrinopathy (hypothyroidism and gestational diabetes mellitus) in study patients.

\begin{tabular}{|lll|}
\hline Dual endocrinopathy & Number of patients & $\%$ \\
\hline Present & 39 & 9.75 \\
\hline Absent & 361 & 90.25 \\
\hline Total & $\mathbf{4 0 0}$ & $\mathbf{1 0 0}$ \\
\hline
\end{tabular}

According to Table 8, 9.75\% (39 out of 400) patients had dual endocrinopathy (both hypothyroidism and gestational diabetes mellitus) while $90.25 \%$ (361 out of 400) did not have dual endocrinopathy (both hypothyroidism and gestational diabetes mellitus).

\section{DISCUSSION}

Preeclampsia is a multiorgan disorder of pregnancy and a leading cause of maternal and perinatal morbidity and mortality. Predisposing factors for this deadly disorder are nulliparity, black race, younger age, low socioeconomic status, obesity, diabetes. Although there are no reliable, valid and economic screening tests available for predicting this pregnancy related disease, some studies have shown association between the levels of thyroid hormones and development of preeclampsia. Preeclampsia women show high incidence of hypothyroidism that might correlate with the severity of preeclampsia. ${ }^{15}$ Different studies have shown that mean serum TSH were significantly elevated in preeclampsia women. ${ }^{16}$ Some studies showed that serum levels of serum TSH were increased in women with severe preeclampsia when compared to mild preeclampsia. ${ }^{17}$

Gestational diabetes and preeclampsia have been postulated to be an early expression of metabolic syndrome. Wendland EM et al in 2008 conducted a study according to which gestational diabetes and preeclampsia have a similar profile of risk factors. ${ }^{18}$ Taking into account that the global prevalence of Gestational Diabetes Mellitus has increased over the past decades this would certainly result in increased number of pregnant women with diabetes.

There is a need to focus on the combined morbidity of hypothyroidism and gestational diabetes mellitus in the patients of preeclampsia Therefore the early identification and treatment of hypothyroidism and gestational diabetes mellitus may affect the occurrence and severity of the morbidity and mortality associated with preeclampsia.

Strength of the study was that it was an observational cross sectional study, and sample size was good $(n=400)$ while limitations of the study was that no controls were taken in the study and the study could not establish the correlation between dual endocrinopathy and preeclampsia due to lack of controls.

\section{CONCLUSION}

The current study concluded that dual endocrinopathy (both hypothyroidism and gestational diabetes mellitus) has substantially higher prevalence $(9.75 \%)$ in the patients of preeclampsia. Therefore, the current study emphasises to manage preeclampsia pregnancies with extra care. Early identification and appropriate measures might affect the occurrence and severity of morbidity associated with preeclampsia.

The study is of a novel kind which has laid down a strong basis to look for dual endocrinopathy in patients of preeclampsia.

\section{REFERENCES}

1. Martin JN, Owens MY, Keiser SD, Parrish MR, Tam $\mathrm{KB}$, Brewer JM, et al. Standardised mississippi protocol treatment of 190 patients with HELLP syndrome: slowing disease progression and preventing new major maternal morbidity. Hypertens Pregnancy. 2012;31(1):79.

2. Khan KS, Wojdyla D, Say L, Gulmezoglu AM, Van Look PF. WHO analysis of causes of maternal death: a systemic review. Lancet. 2006;367:1066.

3. Berg CJ, Harper MA, Atkinson SM, Bell EA, Brown HL, Hage ML, et al. Preventability of pregnancyrelated deaths. Obstet Gynecol. 2005;106:1228.

4. Roberts JM, Lain KY. Recent insights into the pathogenesis of pre-eclampsia. Placenta. 2002;23:359-72.

5. Ferrara A. Increasing prevalence of gestational diabetes. Diabetes. 2007;30:141.

6. Getahun D, Nath C, Ananth CV, Chavez MR, Smulian JC. Gestational diabetes in the United States: temporal trends 1989 through 2004. Am J Obstet Gynecol. 2008;198:525.

7. Paradisi G, Biaggi A, Ferrazzani S, Decarolis S, Caruso A. Abnormal carbohydrate metabolism during pregnancy. Diabetes Care. 2002;25:560-64.

8. Barahona MJ, Sucunza N, Garcia Patterson A, Hernandez M, Adelantado JM, Ginovart G, et al. Period of gestational diabetes mellitus diagnosis and maternal and fetal morbidity. Acta Obstet Gynecol Scand. 2005;84(7):622-7.

9. Beau SO, Mandel SJ. Thyroid disorders during pregnancy Endocrinol Metab Clin North Am. 2006;35(1):117-36.

10. Poppe K, Glinoer D. Thyroid autoimmunity and hypothyroidism before and during pregnancy. Hum Reprod Update. 2003;9(2):149-61.

11. Barber KJ, Franklyn IA, Mc Cabe CJ, Khanim FC, Bulmer JN, Whittey GSJ, Rowan J. The in-vitro effects of thyroid hormone on trophoblast. J Clin Endocrinal Metab. 2005;90(3):1655-61. 
12. Levine RJ, Vatten LJ, Horowitz GL, Qian C, Romundstad PR, Yu KF, et al. Pre-eclampsia, soluble fms-like tyrosine Kinase 1 and the risk of reduced thyroid function. BMJ. 2009;339:43-8.

13. Sahu MT, Das V, Mittal S, Aggarwal A, Sahu M. Overt and subclinical thyroid dysfunction among Indian pregnant women and its effect on maternal and fetal outcome. Arch Gynecol Obstet. 2010;281(2):215-20.

14. Betti M, Ceccatelli G, Belcari F, Moscuzza F, Cuttano A, Vuerich $\mathrm{M}$ et al. Neonatal outcome in newborns from mothers with endocrinopathies. Gynecol Endocrinol. 2011;27(4):248-50.

15. Kaya E, Sahin Y, Ozkececi Z, Pasaoglu H. Relation between birth weight and thyroid function in preeclampsia eclampsia. Gynaecol Obstet Invest. 1994;37:30-3.

16. Kumar A, Ghosh BK, Murthy NS. Maternal thyroid hormonal status in preeclampsia. Indian $\mathrm{J}$ Med Sci. 2005;59(2):57-63.
17. Larijani B, Marsoosi V, Aghakhani S, Moradi A, Hashemipour S. Thyroid hormone alteration in pre eclamptic women. Gynecol Endocrinol. 2004;18(2):97-100.

18. Wendland EM, Duncan BB, Belizan JM, Vigo A, Schmidt MI. Gestational diabetes and pre-eclampsia: common antecedents? Arq Bras Endocrinol Metabol. 2008;52(6):975-84.

Cite this article as: Gupta N, Sharma S, Jamwal S. Prevalence of dual endocrinopathy (hypothyroidism and gestational diabetes mellitus) in patients of preeclampsia. Int J Reprod Contracept Obstet Gynecol 2019;8:4700-4. 